\title{
Clipping aneurysms improves outcomes for patients undergoing coiling
}

\author{
Ian A. Anderson, FRCS(SN), ${ }^{1}$ Ahilan Kailaya-Vasan, FRCS(SN), ${ }^{1}$ \\ Richard J. Nelson, MA, FRCS(Eng), FRCS(Ed), ${ }^{2,3}$ and Christos M. Tolias, PhD, FRCS(SN) ${ }^{1}$ \\ 1Department of Neurosurgery, King's College Hospital NHS Foundation Trust, London, United Kingdom; '2Department of \\ Neurosurgery, Southmead Hospital, Bristol, United Kingdom; and ${ }^{3}$ Neurosurgical National Audit Programme, Society of British \\ Neurological Surgeons, London, United Kingdom
}

\begin{abstract}
OBJECTIVE Most intracranial aneurysms are now treated by endovascular rather than by microsurgical procedures. There is evidence to demonstrate superior outcomes for patients with aneurysmal subarachnoid hemorrhage (aSAH) treated by endovascular techniques. However, some cases continue to require microsurgery. The authors have examined the relationship between the number of aneurysms treated by microsurgery and outcome for patients undergoing treatment for aSAH at neurosurgical centers in England.
\end{abstract}

METHODS The Neurosurgical National Audit Programme (NNAP) database was used to identify aSAH cases and to provide associated 30-day mortality rates for each of the 24 neurosurgical centers in England. Data were compared for association by regression analysis using the Pearson product-moment correlation coefficient and any associations were tested for statistical significance using the one-way ANOVA test. The NNAP data were validated utilizing a second, independent registry: the British Neurovascular Group's (BNVG) National Subarachnoid Haemorrhage Database.

RESULTS Increasing numbers of microsurgical cases in a center are associated with lower 30-day mortality rates for all patients treated for aSAH, irrespective of treatment modality (Pearson $r=0.42, p=0.04$ ), and for patients treated for aSAH by endovascular procedures (Pearson $r=0.42, p=0.04$ ). The correlations are stronger if all (elective and acute) microsurgical cases are compared with outcome. The BNVG data validated the NNAP data set for patients with aSAH.

CONCLUSIONS There is a statistically significant association between local microsurgical activity and center outcomes for patients with aSAH, even for patients treated endovascularly. The authors postulate that the number of microsurgical cases performed may be a surrogate indicator of closer neurosurgical involvement in the overall management of neurovascular patients and of optimal case selection.

https://thejns.org/doi/abs/10.3171/2017.12.JNS172759

KEYWORDS cerebral aneurysm; subarachnoid hemorrhage; clip; coil; Neurosurgical National Audit Programme; NNAP; vascular disorders

$\mathrm{O}$ VER the last 25 years there has been a progressive change in the management of elective and ruptured intracranial aneurysms such that the majority of cases are now treated by endovascular rather than by open microsurgical procedures. This proportion continues to rise. ${ }^{1,13}$ Several large prospective trials as well as a systematic review and meta-analysis of the published outcomes for patients presenting with aneurysmal subarachnoid hemorrhage (aSAH) have demonstrated better outcomes for patients treated by endovascular means, despite a higher risk of rebleeding in this cohort. ${ }^{7,910}$ The evidence is less clear for patients undergoing elective treatment of unruptured aneurysms..$^{1,4,14}$

Despite the established place of endovascular treatment, a significant minority of intracranial aneurysms may be better treated microsurgically due to factors such as concurrent hematoma evacuation; aneurysm morphology and location; and patient age and preference. Since there are no firm guidelines on which aneurysms should still be treated surgically, practice varies from center to center. Although endovascular procedures for intracranial aneurysms are performed almost exclusively by interven-

ABBREVIATIONS aSAH = aneurysmal subarachnoid hemorrhage; BNVG = British Neurovascular Group; HES = Hospital Episode Statistics; NHS = National Health Service; NNAP = Neurosurgical National Audit Programme; ONS = Office for National Statistics.

SUBMITTED November 1, 2017. ACCEPTED December 23, 2017.

INCLUDE WHEN CITING Published online June 8, 2018; DOI: 10.3171/2017.12.JNS172759. 
tional neuroradiologists in English centers, the overall clinical management of aSAH patients typically remains the responsibility of the neurosurgeon.

The Neurosurgical National Audit Programme (NNAP) is a quality improvement initiative established by the Society of British Neurological Surgeons that collates data regarding neurosurgical center activity and outcome (https://www.hed.nhs.uk/sbns). The database includes all 24 English neurosurgical centers, covering a population of approximately 54 million people. The data are acquired from the National Health Service (NHS) Hospital Episode Statistics (HES) database and the Office for National Statistics (ONS).

In this study, we used NNAP data to examine whether the number of aneurysms treated by microsurgery is linked to outcome for all patients undergoing treatment, either surgical or endovascular, for aSAH in England.

\section{Methods}

The NNAP database was searched for all adult $(\geq 17$ years on admission) admissions during the three-year period from April 1, 2013, to March 31, 2016. The BNVG provided permission to use its database to validate the NNAP data.

All cases of aneurysms treated by microsurgery (defined by NNAP as episodes with HES OPCS4 procedural codes L331, L332, L333, L334, or L338) or by endovascular means (defined by NNAP as episodes with HES OPCS4 procedural codes L351, L353, L358, O011, O012, O013, O014, O018, O019, O021, O022, O023, O028, O029, O031, O032, O033, O038, O039, O041, O042, O048, O049, O051, O052, or O053) were included for analysis.

The NNAP database classifies admissions as either elective or nonelective. In the first part of this study, all nonelective admissions were assumed to be due to aSAH and are therefore referred to as acute cases. Elective admissions were excluded from the first analysis. In the second part of the study elective microsurgical aneurysm procedures in the same period were added to give a complete representation of center microsurgical activity. The 30-day mortality rates derived by the NNAP from centrally validated ONS data were recorded for all centers and for each treatment modality.

The study variables were compared for association by regression analysis using the Pearson product-moment correlation coefficient, and any associations were tested for statistical significance using the one-way ANOVA test.

Data validation was undertaken utilizing a second, independent registry of English SAH patients: the British Neurovascular Group (BNVG) Subarachnoid Haemorrhage Database (http://neurovascular.co.uk). The BNVG database is an online resource that records treatment and outcomes of patients treated for SAH at neurosurgical centers in the United Kingdom and Ireland. Data are submitted by the participating centers voluntarily. Currently 12 English centers submit data. This database was searched for the same 3-year period as was the NNAP database to ascertain whether the NNAP data were a representative data set.

\section{Results}

A total of 6450 aSAH procedures were performed in 3 years: 5515 (85.5\%) were endovascular and 935 (14.5\%) were microsurgical. The proportion of endovascular aSAH procedures undertaken at individual centers varied considerably, from $54.0 \%$ to $97.9 \%$. The national 30-day mortality rate following acute endovascular procedures was $352 / 5515(6.4 \%)$, and the 30-day mortality rate following acute microsurgical procedures was 80/935 (8.6\%). The median combined number of acute procedures performed per center was 276 (range 102 to 432).

A funnel plot (Fig. 1) of 30-day mortality against the number of acute aSAH procedures performed demonstrated that no neurosurgical center mortality rates fell outside

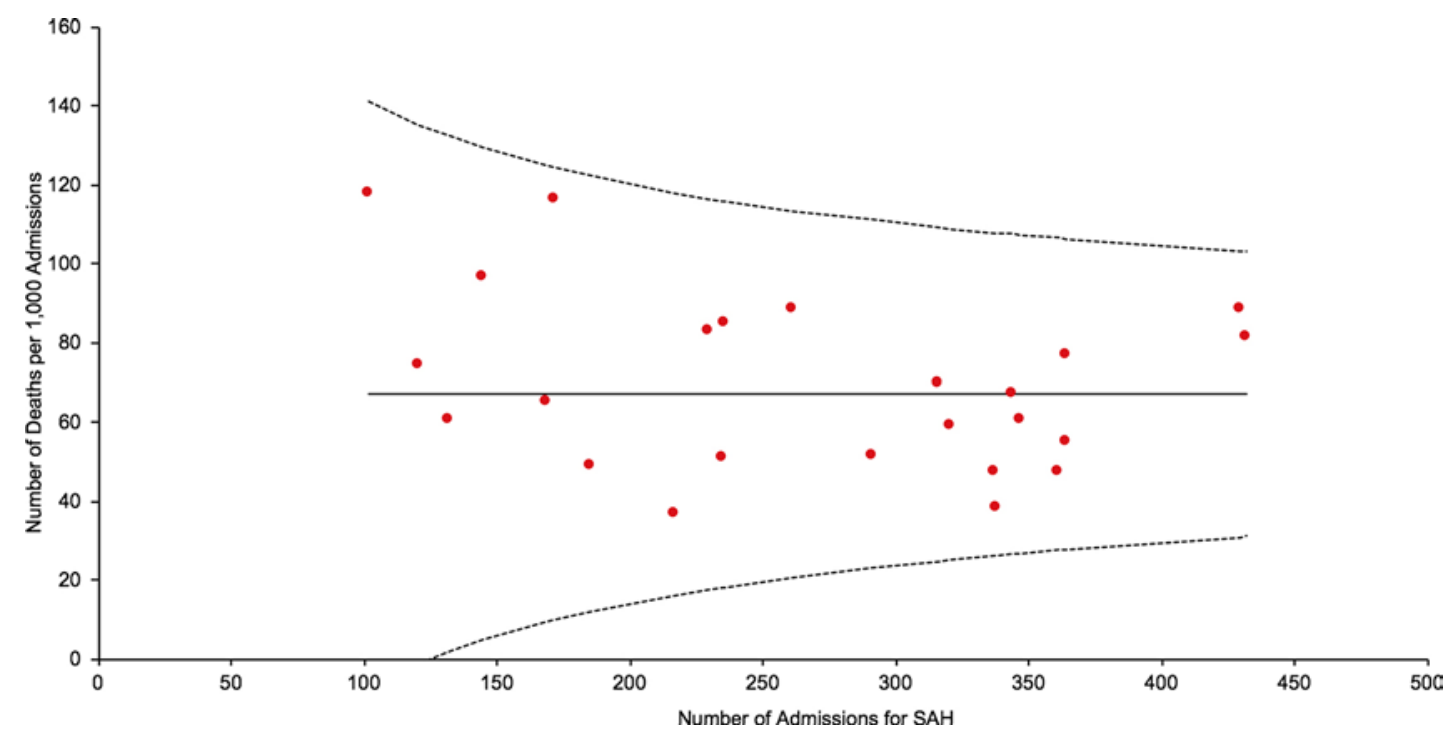

FIG. 1. Funnel plot showing the 30 -day mortality rates (per 1000 admissions) for patients admitted and treated for aSAH. Dashed lines represent $95 \%$ confidence intervals. Figure is available in color online only. 
of the $95 \%$ confidence intervals (marked). There was no significant correlation between acute aSAH case volume and center 30-day mortality rates (Pearson $\mathrm{r}=0.17, \mathrm{p}=$ 0.44).

There was no significant relationship between the number of endovascular cases performed in each center and 30-day endovascular mortality rates (Pearson $\mathrm{r}=0.13, \mathrm{p}$ $=0.54)$.

An association between the number of microsurgical cases performed in each center and 30-day microsurgical mortality rates did not achieve statistical significance (Pearson $\mathrm{r}=0.37, \mathrm{p}=0.08$ ) (Fig. 2). When the proportion of acute aneurysms treated microsurgically was compared with the 30-day microsurgical mortality rates, the relationship was statistically significant (Pearson $\mathrm{r}=0.43, \mathrm{p}$ $=0.03$ ).

A significant relationship existed between the number of microsurgical procedures performed in each center and the center 30-day mortality rates for all patients treated for aSAH, irrespective of treatment modality (Pearson $\mathrm{r}=$ $0.42, \mathrm{p}=0.04)$.

There was also a significant correlation between the number of microsurgical aSAH procedures performed in a center and the center mortality rate for aSAH patients treated by endovascular procedures (Pearson $\mathrm{r}=0.42, \mathrm{p}=$ 0.04) (Fig. 3).

A total of 600 elective microsurgical aneurysmal procedures were performed in England during the study period, in addition to the 935 acute microsurgical procedures, making a total of 1535 procedures. The correlation between the number of microsurgical procedures performed and 30-day mortality rates was strengthened by the inclusion of the elective aneurysm procedures (Pearson $\mathrm{r}=$ 0.54, $\mathrm{p}=0.01$ ) (Fig. 4).

There was also a significant correlation between the total number of microsurgical procedures (acute and elective) performed in a neurosurgical center and outcome for aSAH patients treated at that center by endovascular means only (Pearson $r=0.48, p=0.02$ ) (Fig. 5).

Interestingly, the overall number of aneurysms treated in a center (acute and elective; endovascular and microsurgical) had no significant relationship to the departmental aSAH mortality rate (Pearson $r=0.11, p=0.62$ ) or the mortality rate for all treated aneurysms (Pearson $\mathrm{r}=0.18$, $\mathrm{p}=0.40)$.

Twelve of the 24 centers in the NNAP database also submitted data to the BNVG database. A comparison of the BNVG data and the NNAP data center is shown in Table 1. The number of procedures performed and the proportion of aneurysms treated by each method in the BNVG data validate the NNAP data. As data in this registry are center anonymized direct statistical comparison was not possible.

When the NNAP database was used to compare the results of centers that contribute to the BNVG database with those that do not, the centers that contributed to the BNVG database performed a significantly higher number of microsurgical procedures for aSAH. Centers contribut-

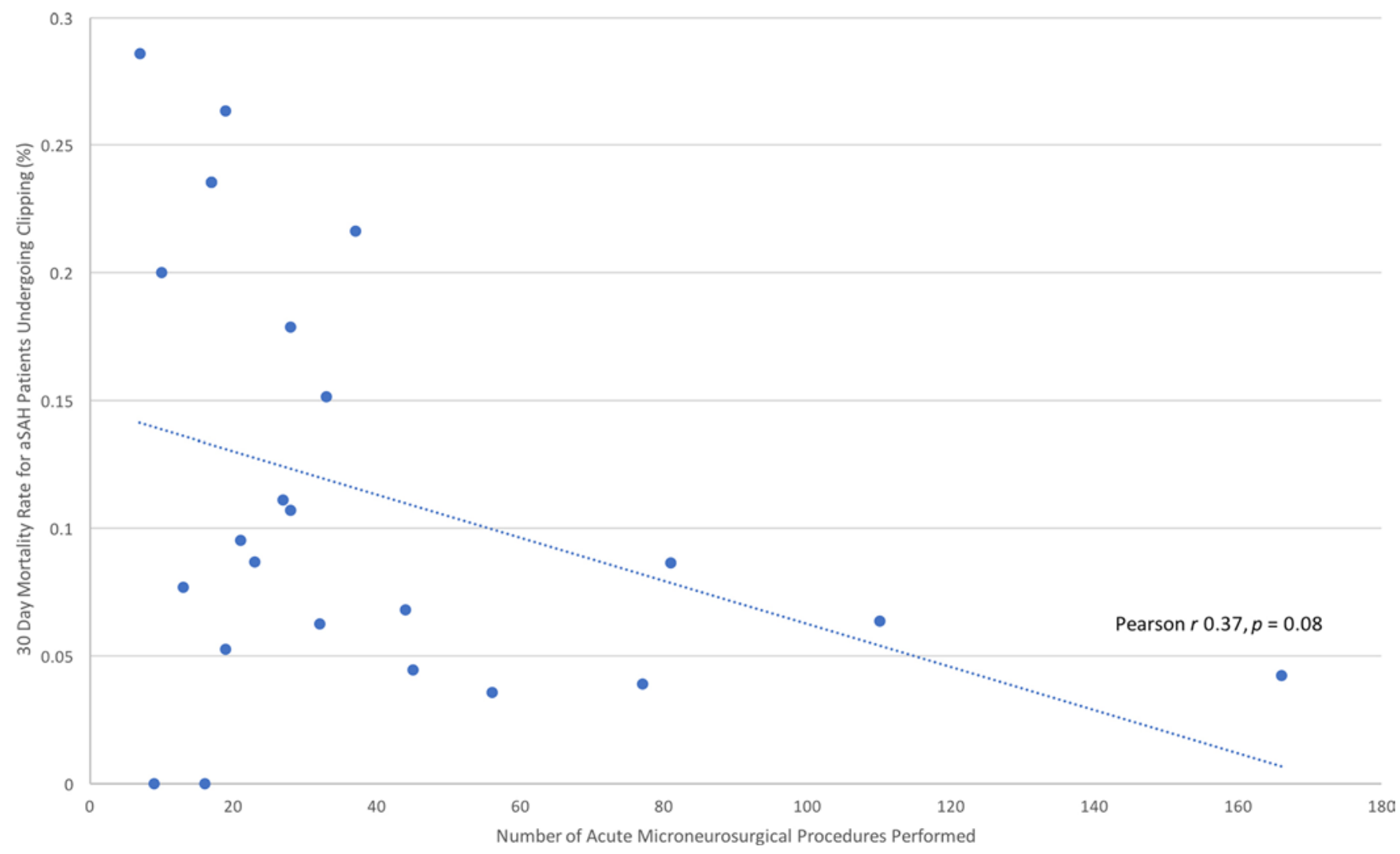

FIG. 2. Scatter plot of 30-day mortality rates following acute microsurgical clipping procedures against the number of acute microsurgical clipping procedures performed per neurosurgical center. Figure is available in color online only. 
I. A. Anderson et al.

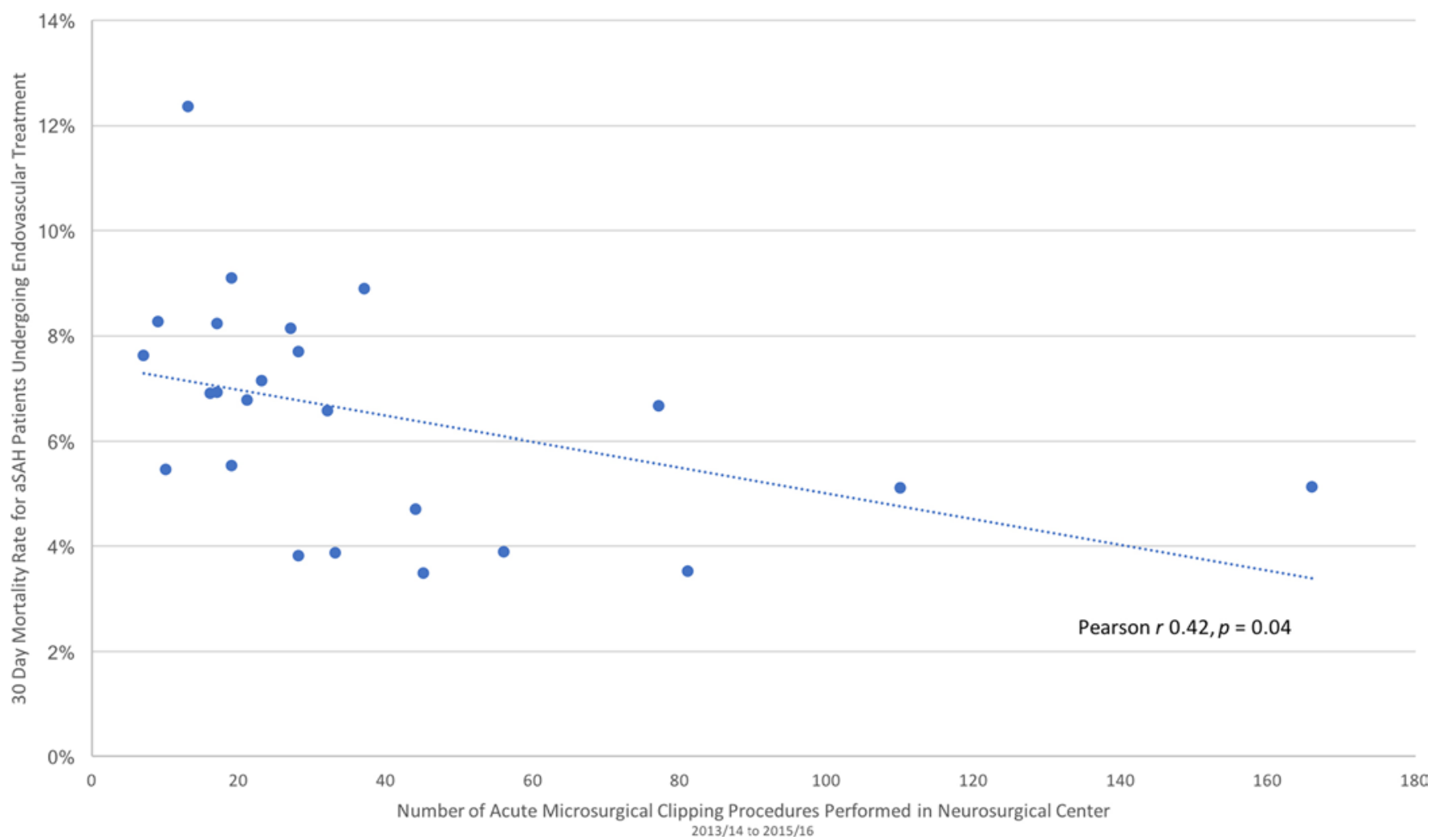

FIG. 3. Scatter plot of 30-day mortality rates following acute endovascular procedures against the number of acute microsurgical clipping procedures performed per neurosurgical center. Figure is available in color online only.

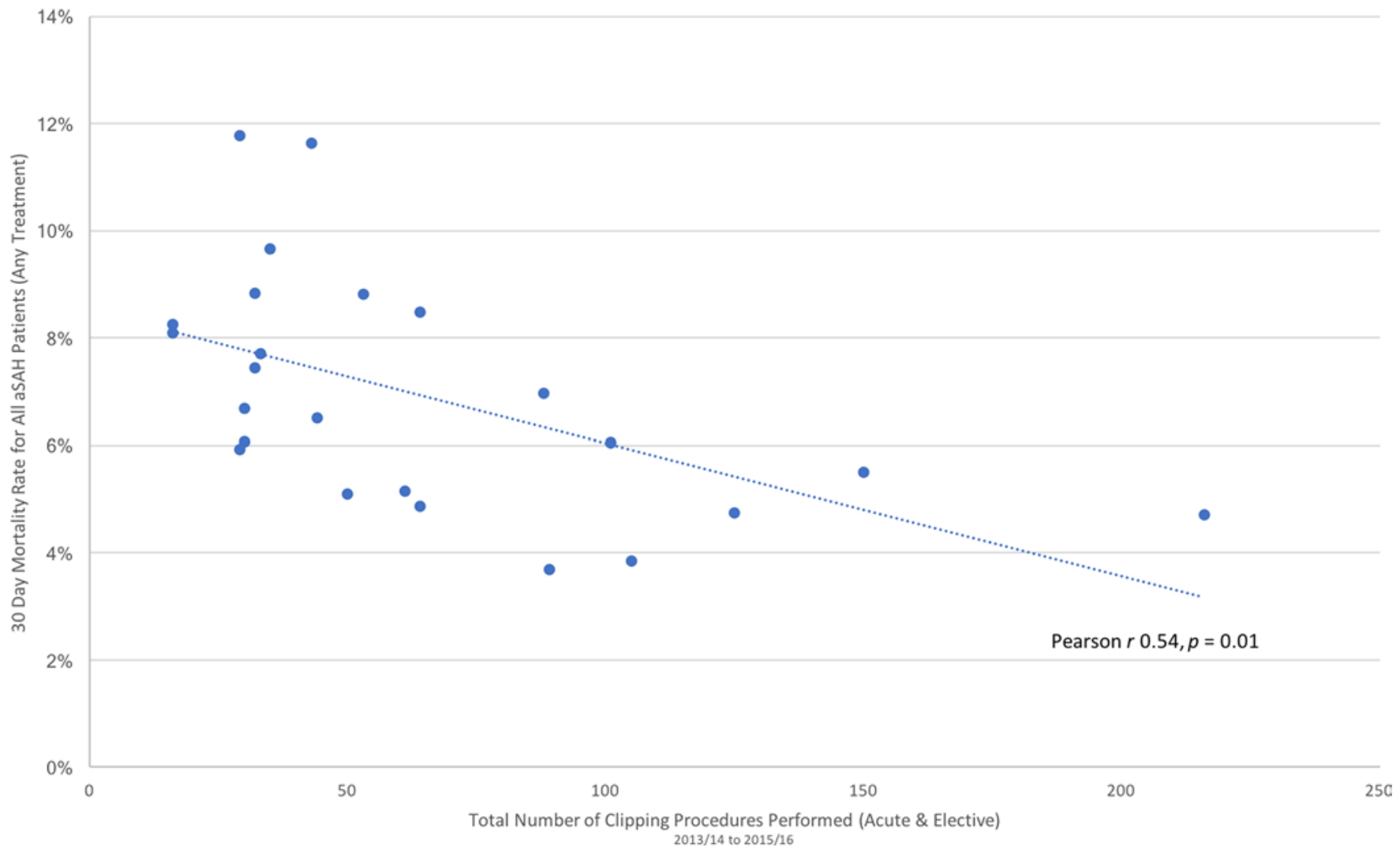

FIG. 4. Scatter plot of 30-day mortality rates following acute endovascular procedures against the number of acute microsurgical clipping procedures performed per neurosurgical center. Figure is available in color online only. 


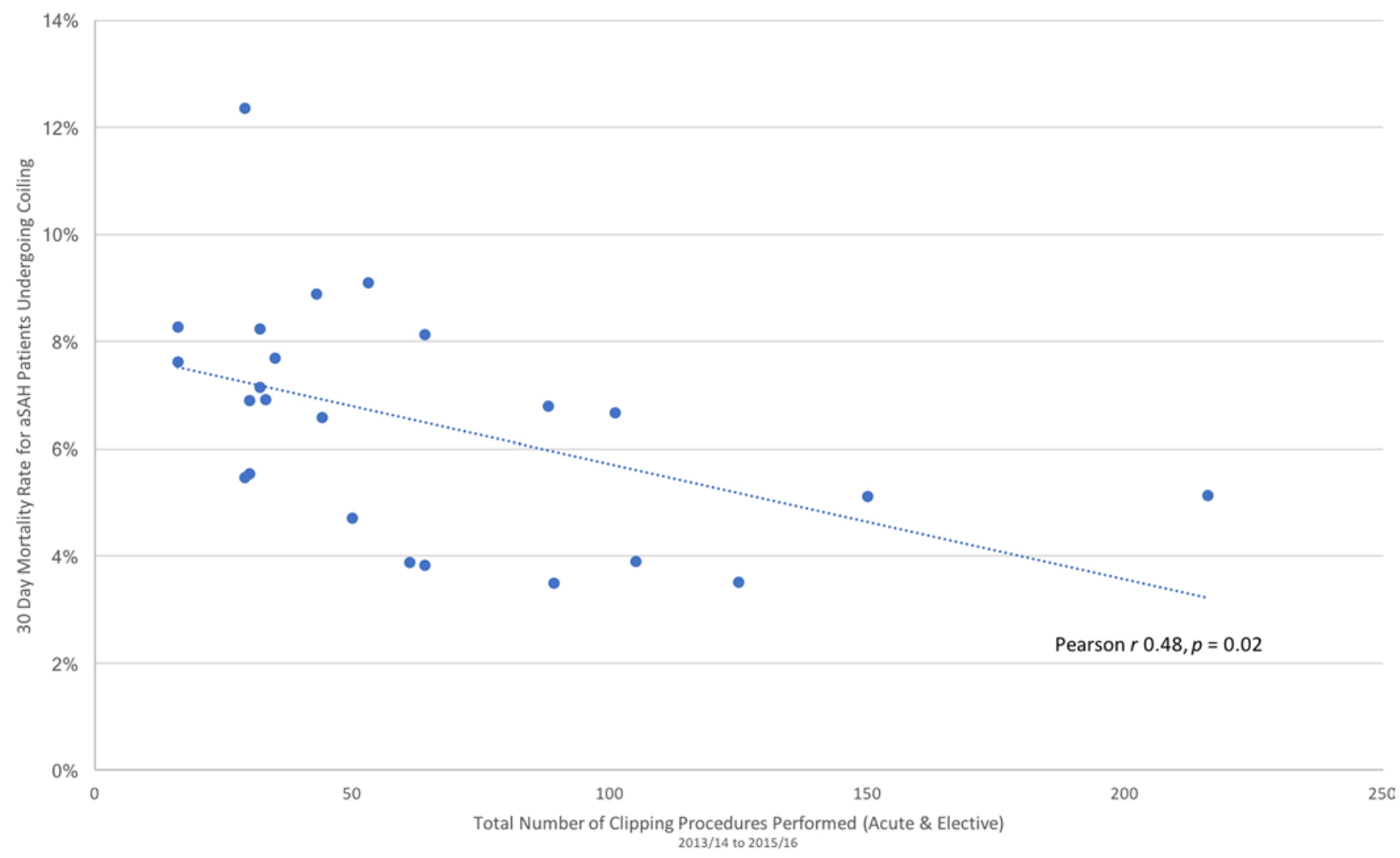

FIG. 5. Scatter plot of 30-day mortality rates following any treatment for aSAH against the total number of microsurgical clipping procedures performed (acute and elective cases) per neurosurgical center. Figure is available in color online only.

ing to the BNVG database had significantly lower overall mortality rates for patients treated for aSAH as well as significantly lower microsurgical 30-day mortality rates. The 30-day mortality rate following endovascular procedures was also lower in centers contributing to the BNVG database, but the difference did not achieve statistical significance (Table 2).

\section{Discussion}

We have demonstrated that there is a significant association between increasing microsurgical workload in a center and improved outcome for patients with aSAH, irrespective of the modality by which the acute aneurysm was treated. Furthermore, increasing neurovascular microsurgical workload was associated with improved outcomes in the patients treated endovascularly. This phenomenon has not previously been described.

The observation that both the increased number and increased proportion of acute cases being treated by microsurgical means are associated with improved microsurgical 30-day mortality rates suggests that the reason for the improved outcomes seen in the endovascular group is not simply that patients with a poorer prognosis are being selected for microsurgery.

A correlation between increasing caseload and improved outcome has been previously described in neurovascular centers for both microsurgical and endovascular procedures. , $, 5,6,11,12$ However, in our study neither increased overall workload nor increased endovascular workload was significantly correlated with post-endovascular treatment outcome; only microsurgical throughput was significant. Given the lack of significant association between total aSAH case volume or total number of aneurysms treated (by any method) and 30-day mortality rates following aSAH treatment, we conclude that the differences that were observed within our study are not simply a demonstration of high volume improving outcome.

TABLE 1. Comparison of data obtained from NNAP and BNVG regarding number and proportion of endovascular and microsurgical procedures performed in England

\begin{tabular}{lcc}
\hline \multicolumn{1}{c}{ Procedure } & NNAP Database* $^{*}$ & BNVG Database† \\
\hline Total aSAH ops & 3330 & 2808 \\
\hline $\begin{array}{l}\text { Microsurgical aSAH } \\
\text { ops }\end{array}$ & $554(16.6 \%)$ & $575(20.5 \%)$ \\
\hline $\begin{array}{l}\text { Endovascular aSAH } \\
\text { ops }\end{array}$ & $2776(83.4 \%)$ & $2233(79.5 \%)$ \\
\hline $\begin{array}{l}\text { Median proportion of } \\
\text { aSAH cases treated } \\
\text { endovascularly } \\
\text { (range) }\end{array}$ & $86.4 \%$ & $87.7 \%$ \\
\hline
\end{tabular}

* Excluding data from centers that do not contribute to the BNVG database. $\dagger$ Excluding data from centers in Ireland, Northern Ireland, Scotland, and Wales. 
TABLE 2. Comparison of outcomes and aSAH case mix of English neurosurgical centers that contribute to the BNVG database and those that do not contribute

\begin{tabular}{|c|c|c|c|}
\hline Procedure & Centers Contributing to BNVG Database* & Centers Not Contributing to BNVG Database* & Chi-Square Test \\
\hline No. of centers in cohort & 12 & 12 & - \\
\hline Total no. of aSAH ops & 3330 & 3120 & - \\
\hline No. of endovascular ops & 2776 & 2739 & - \\
\hline No. of microsurgical ops & 554 & 381 & - \\
\hline Microsurgical proportion of ops & $16.6 \%$ & $12.2 \%$ & $\chi^{2}=25.4, p<0.001$ \\
\hline Overall aSAH 30-day mortality rate & $6.1 \%$ & $7.3 \%$ & $\chi^{2}=4.0, p=0.046$ \\
\hline Endovascular 30-day mortality rate & $5.9 \%$ & $6.9 \%$ & $\chi^{2}=2.1, p=0.146$ \\
\hline Microsurgical 30-day mortality rate & $7.0 \%$ & $10.8 \%$ & $\chi^{2}=4.0, p=0.046$ \\
\hline
\end{tabular}

$-=$ not applicable.

Boldface type indicates statistical significance.

${ }^{*}$ Excluding centers in Ireland, Northern Ireland, Scotland, and Wales.

While we have been able to disprove the hypothesis that overall high volume is the cause for better outcome in certain centers, this study cannot determine causality. It seems implausible that the frequency of performing microsurgery for some aSAH patients would directly improve the outcomes of endovascular procedures for other aSAH patients, which nearly always would have been performed by a different clinician.

There are several possible explanations for our findings. The number of microsurgical aneurysm procedures performed in a center may be a surrogate indicator for factors that $d o$ affect outcome for endovascular patients, such as more direct involvement in the ongoing care of neurovascular patients by surgeons. The observation that the centers that contribute to the BNVG database have lower mortality rates than those that do not may support the proposition that greater neurosurgical involvement in patient care promotes better patient outcomes.

We speculate that in centers where neurosurgeons are more frequently clipping aneurysms, there might be better multidisciplinary interaction between neuroradiology and neurosurgery teams, leading to better case selection. More experienced neurosurgeons may suggest clipping as an appropriate treatment for aneurysms that represent higherrisk endovascular targets, thereby reducing the complication rate for endovascularly treated aSAH.

It is also possible that our findings are due to differences in the aSAH admission policies of centers such that high-surgical volume centers admit fewer poor-grade aSAH patients than low-surgical volume centers, resulting in better endovascular outcomes. However, this is not borne out by the overall outcomes of the 24 centers in the study. Clearly, more investigation of this newly described relationship is required to establish the cause for the results observed.

This study is limited by the hospital activity data that are available for analysis by the NNAP. Important prognostic variables, such as clinical grade and CT blood load, are not included in routine hospital coding, which prevents multivariate analysis.

The NNAP database includes all hospital admissions that are attributed to a consultant neurosurgeon using a specialty-specific code-150. Inaccuracies in hospital coding are well documented. ${ }^{2,8}$ Small numbers of aSAH patients may be admitted under the care of other specialists, but these patients are then transferred to the care of a neurosurgeon if they undergo a procedure. The close correlation between the NNAP data and the independently collected BNVG data indicates that coding errors are unlikely to explain our findings. It would require a substantial number of poor-outcome endovascularly treated patients in high-surgical volume centers to be miscoded or misattributed to other consultants. ${ }^{2}$

\section{Conclusions}

We have identified a previously undescribed, significant association between the number of microsurgical aneurysm procedures performed in a neurosurgical center and improved outcome for patients treated for aSAH, even those treated by endovascular means.

The reason for this association remains unclear. However, we suggest that this study highlights the importance of robust, well-supported neurovascular multidisciplinary teams with engaged and surgically active neurovascular neurosurgeons in the management of aSAH patients.

\section{Acknowledgments}

We would like to thank the chair of the NNAP, Mr. Nick Phillips, for approving the use of the database for this paper. We would also like to acknowledge Mr. J. P. Galea, Ms. L. Dulhanty, Mr. H. C. Patel, and Mr. D. C. Walsh for their efforts in creating, maintaining, and helping to interrogate the BNVG Subarachnoid Haemorrhage Database. Additionally, we thank Paul Bassett of Statsconsultancy Ltd. for peer reviewing the statistical methodology employed in this study.

\section{References}

1. Alshekhlee A, Mehta S, Edgell RC, Vora N, Feen E, Mohammadi A, et al: Hospital mortality and complications of electively clipped or coiled unruptured intracranial aneurysm. Stroke 41: 1471-1476, 2010

2. Burns EM, Rigby E, Mamidanna R, Bottle A, Aylin P, Ziprin $\mathrm{P}$, et al: Systematic review of discharge coding accuracy. J Public Health (Oxf) 34:138-148, 2012

3. Cross DT III, Tirschwell DL, Clark MA, Tuden D, Derdeyn 
CP, Moran CJ, et al: Mortality rates after subarachnoid hemorrhage: variations according to hospital case volume in 18 states. J Neurosurg 99:810-817, 2003

4. Darsaut TE, Findlay JM, Magro E, Kotowski M, Roy D, Weill A, et al: Surgical clipping or endovascular coiling for unruptured intracranial aneurysms: a pragmatic randomised trial. J Neurol Neurosurg Psychiatry 88:663-668, 2017

5. Davies JM, Lawton MT: Improved outcomes for patients with cerebrovascular malformations at high-volume centers: the impact of surgeon and hospital volume in the United States, 2000-2009. J Neurosurg 127:69-80, 2017

6. Leake CB, Brinjikji W, Kallmes DF, Cloft HJ: Increasing treatment of ruptured cerebral aneurysms at high-volume centers in the United States. J Neurosurg 115:1179-1183, 2011

7. Li H, Pan R, Wang H, Rong X, Yin Z, Milgrom DP, et al: Clipping versus coiling for ruptured intracranial aneurysms: a systematic review and meta-analysis. Stroke 44:29-37, 2013

8. Maringe C, Fowler H, Rachet B, Luque-Fernandez MA: Reproducibility, reliability and validity of population-based administrative health data for the assessment of cancer nonrelated comorbidities. PLoS One 12:e0172814, 2017

9. McDougall CG, Spetzler RF, Zabramski JM, Partovi S, Hills NK, Nakaji P, et al: The Barrow Ruptured Aneurysm Trial. J Neurosurg 116:135-144, 2012

10. Molyneux A, Kerr R, Stratton I, Sandercock P, Clarke M, Shrimpton J, et al: International Subarachnoid Aneurysm Trial (ISAT) of neurosurgical clipping versus endovascular coiling in 2143 patients with ruptured intracranial aneurysms: a randomised trial. Lancet 360:1267-1274, 2002

11. Natarajan SK, Sekhar LN, Ghodke B, Britz GW, Bhagawati $\mathrm{D}$, Temkin N: Outcomes of ruptured intracranial aneurysms treated by microsurgical clipping and endovascular coiling in a high-volume center. AJNR Am J Neuroradiol 29:753-759, 2008

12. Pandey AS, Gemmete JJ, Wilson TJ, Chaudhary N, Thomp- son BG, Morgenstern LB, et al: High subarachnoid hemorrhage patient volume associated with lower mortality and better outcomes. Neurosurgery 77:462-470, 2015

13. Tykocki T, Kostyra K, Czyż M, Kostkiewicz B: Four-year trends in the treatment of cerebral aneurysms in Poland in 2009-2012. Acta Neurochir (Wien) 156:861-868, 2014

14. Wiebers DO, Whisnant JP, Huston J III, Meissner I, Brown RD Jr, Piepgras DG, et al: Unruptured intracranial aneurysms: natural history, clinical outcome, and risks of surgical and endovascular treatment. Lancet 362:103-110, 2003

\section{Disclosures}

The authors report no conflict of interest concerning the materials or methods used in this study or the findings specified in this paper.

\section{Author Contributions}

Conception and design: Anderson, Tolias. Acquisition of data: Anderson. Analysis and interpretation of data: Anderson. Drafting the article: Anderson. Critically revising the article: all authors. Reviewed submitted version of manuscript: all authors. Approved the final version of the manuscript on behalf of all authors: Anderson. Statistical analysis: Anderson.

\section{Supplemental Information}

\section{Previous Presentations}

An abstract that summarized some of the results from this work was presented orally at the BNVG subspecialty meeting at the Society of British Neurological Surgeons (SBNS) meeting, September 19, 2017, Liverpool, United Kingdom.

\section{Correspondence}

Ian Anderson: King's College Hospital NHS Foundation Trust, London, United Kingdom. ian.anderson4@nhs.net. 